\title{
Morphology Dependence in Photothermal Heating of Gold Nanomaterials with Near-Infrared Laser
}

Mazen Alrahili1, ${ }^{*}$, Renju Peroor ${ }^{1}$, Viktoriia Savchuk $^{1}$, Kelly McNear ${ }^{2}$, and Anatoliy Pinchuk ${ }^{1,2}$

${ }^{1}$ Department of Physics and Energy Science, University of Colorado Colorado Springs, 1420 Austin Bluffs Parkway, Colorado Springs, Colorado 80918, USA

${ }^{2}$ UCCS BioFrontiers Center, University of Colorado Colorado Springs, 1420 Austin Bluffs Parkway, Colorado Springs, Colorado 80918, USA

${ }^{3}$ Physics Department, School of Science, Taibah University, Janadah Bin Umayyah Road, Medina 42353, Saudi Arabia

\section{* Corresponding Author}

\author{
Mazen Alrahili
}

E-mail: mrahili@taibahu.edu.sa

This documents contained bar charts of the max temperature changes of 5 GNMs with the dilution of the solution, table of the experimental values, table of the comparison experimental results from different publications, figures of the separation of all heating and cooling GNMs with rate constant of heat losses, figure of the transmitted power 
with different concentration, figures of the separation of all measured and calculated temperature profile, some of SEM and TEM images, schematic showing where the temperature measured, extinction spectra of IR dyes, cooling GNM solution and determining the temperature rate, size determination of GNMs by using dynamic light scattering (DLS), and references.

\section{Maximum Temperature of Five GNMs versus the Concentrations}
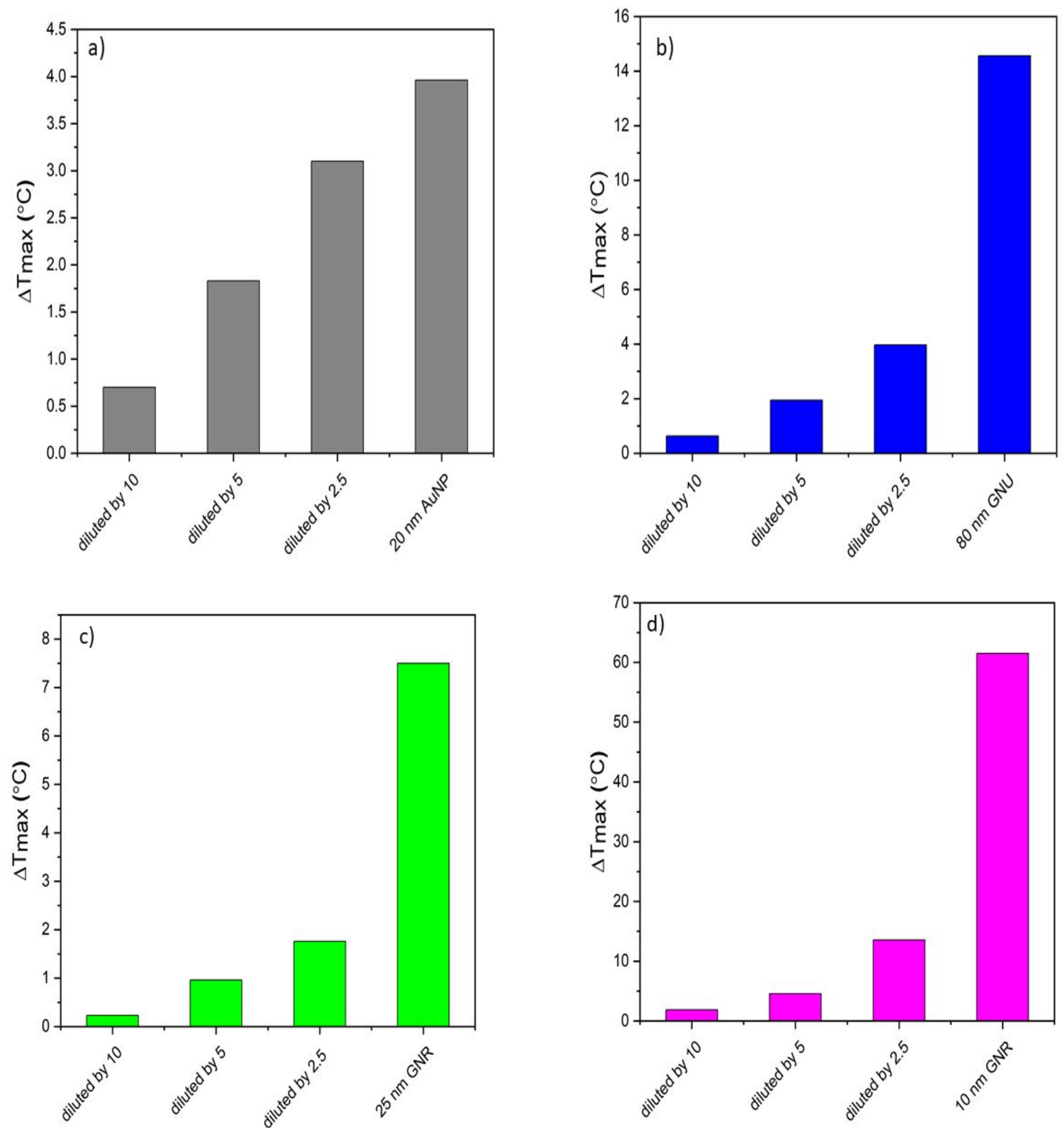


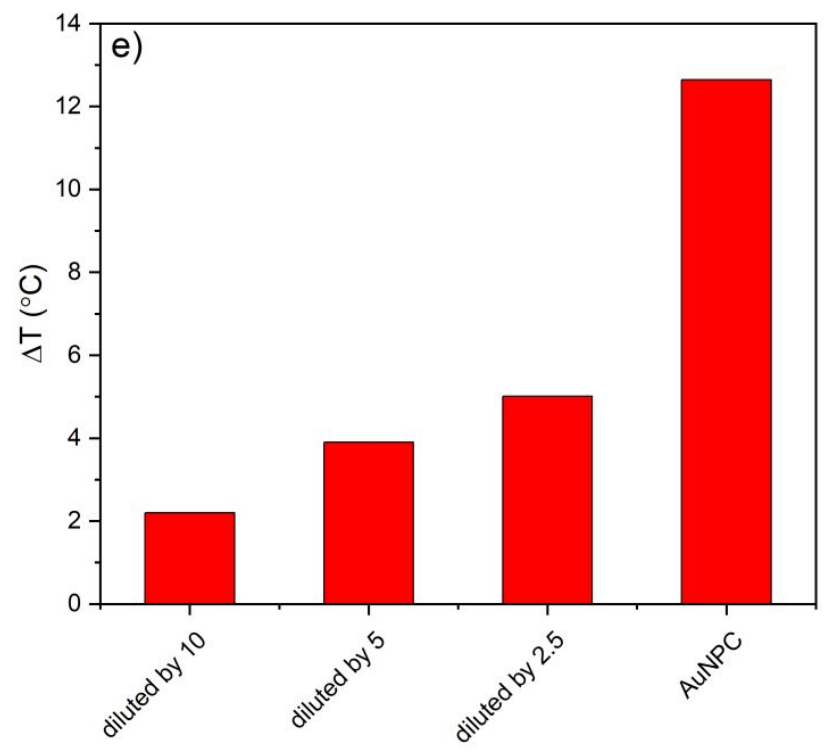

Figure S1. The bar charts represent the maximum temperature versus all GNMs with diluted factors of aqueous solution of (a) $20 \mathrm{~nm}$ AuNPs, (b) $80 \mathrm{~nm}$ GNU, (c) $25 \mathrm{~nm}$ GNR and (d) $10 \mathrm{~nm}$ GNR. The numbers, 20,80,25, and 10, represent the diameters of GNMs.

\section{Experimental Numerical Values Associated with Figure 4}

The incident power for all the measurements is the same ( $I_{0}=3.78$ Watts) and the mass can be determined by the following Eq. $\mathrm{m}=\rho_{m} V$

where $\rho_{m}$ is the density of water at room temperature $(0.997 \mathrm{~g} / \mathrm{mL})$ and $V$ is the volume of the water in the container $(3 \mathrm{~mL})$. Therefore, the mass is $2.991 \mathrm{~g}$ for all samples and $\mathrm{S}=19.2 \mathrm{~cm}^{2}$.

Table S1. The parameters associated with figure 4.

\begin{tabular}{|lcclcc|}
\hline Parameters & $\mathbf{2 0} \mathbf{~ n m ~ A u N P s}$ & $\mathbf{8 0} \mathbf{~ n m ~ G N U s}$ & $\begin{array}{l}\mathbf{6 5 0} \mathbf{~ n m} \text { abs. } \\
\text { GNRs }\end{array}$ & $\begin{array}{l}\mathbf{8 0 8} \mathbf{~ n m} \text { abs. } \\
\text { GNRs }\end{array}$ & AuNPCs \\
\hline$h\left(\mathrm{~W} / \mathrm{Km}^{2}\right)$ & 14.97 & 13.88 & 14.15 & 20.12 & 26.85 \\
$\mathrm{~B}\left(\mathrm{~s}^{-1}\right)$ & 0.0023 & 0.002132 & 0.00225 & 0.00309 & 0.004124 \\
$T_{0}\left({ }^{\circ} \mathrm{C}\right)$ & 23 & 23 & 23.1 & 23.3 & 23 \\
$T_{\max }\left({ }^{\circ} \mathrm{C}\right)$ & 26.90 & 37.5 & 32.5 & 84.8 & 35.65 \\
$\mathrm{~T}(\mathrm{t})\left({ }^{\circ} \mathrm{C}\right)$ & 25.59 & 30.143 & 26.65 & 56.76 & 29.19 \\
$I_{t r}(\mathrm{Watt})$ & 2.32 & 2.25 & 2.29 & 0.85 & 1.7 \\
$\lambda_{S P R}(\mathrm{~nm})$ & 524 & 614 & 650 & 808 & 524 \\
$\eta(\%)$ & $7.68(0.28)$ & $25.26(1.53)$ & $17.74(0.57)$ & $81(3.2)$ & $31.35(3.5)$ \\
\hline
\end{tabular}




\section{Comparison between Selected Publications to Determine the $\eta$}

Table S2. Listed experimental results are similar to our experimental instrumentation.NA indicates that the parameters are not available. The references indicate on the top right of the authors' name and the numbers on the diameters column in the parentheses indicate to aspect ratios (AR), length divided by diameter, of GNRs. The time indicates how much the solution was excited by the laser.

\begin{tabular}{|llllcccc|} 
references & $\begin{array}{c}\text { NP } \\
\text { shapes }\end{array}$ & Diameter(nm) & $\begin{array}{l}\text { Laser } \\
\text { power }\end{array}$ & $\begin{array}{c}\text { Laser } \\
\text { wavelength(nm) }\end{array}$ & $\lambda_{\text {SPR }}(\mathbf{n m})$ & $\begin{array}{c}\text { Time } \\
\text { (minutes) }\end{array}$ & $\mathbf{\eta}$ \\
\hline Richardson $^{1}$ & AuNP & 20 & $0.28 \mathrm{~W}$ & 532 & NA & 1.66 & $0.97-1.03$ \\
Jiang $^{2}$ & AuNP & 19 & $0.28 \mathrm{~W}$ & 532 & $\mathrm{NA}$ & 21 & 0.73 \\
Chen $^{3}$ & $G N R$ & $10(3.8)$ & $\mathrm{NA}$ & 809 & 809 & 30 & 0.95 \\
Cole $^{4}$ & $G N R$ & $13(3.38)$ & $\mathrm{NA}$ & 815 & 780 & 40 & 0.59 \\
Pattani $^{5}$ & $G N R$ & $7(3.71)$ & $2 \mathrm{~W}$ & 808 & 770 & 5 & 0.50 \\
Zeng $^{6}$ & $G N R$ & $17(3.29)$ & $0.4 \mathrm{~W}$ & 808 & 810 & 10 & 0.22 \\
\end{tabular}


Heating and Cooling the temperature traces and Determining the Heat Losses
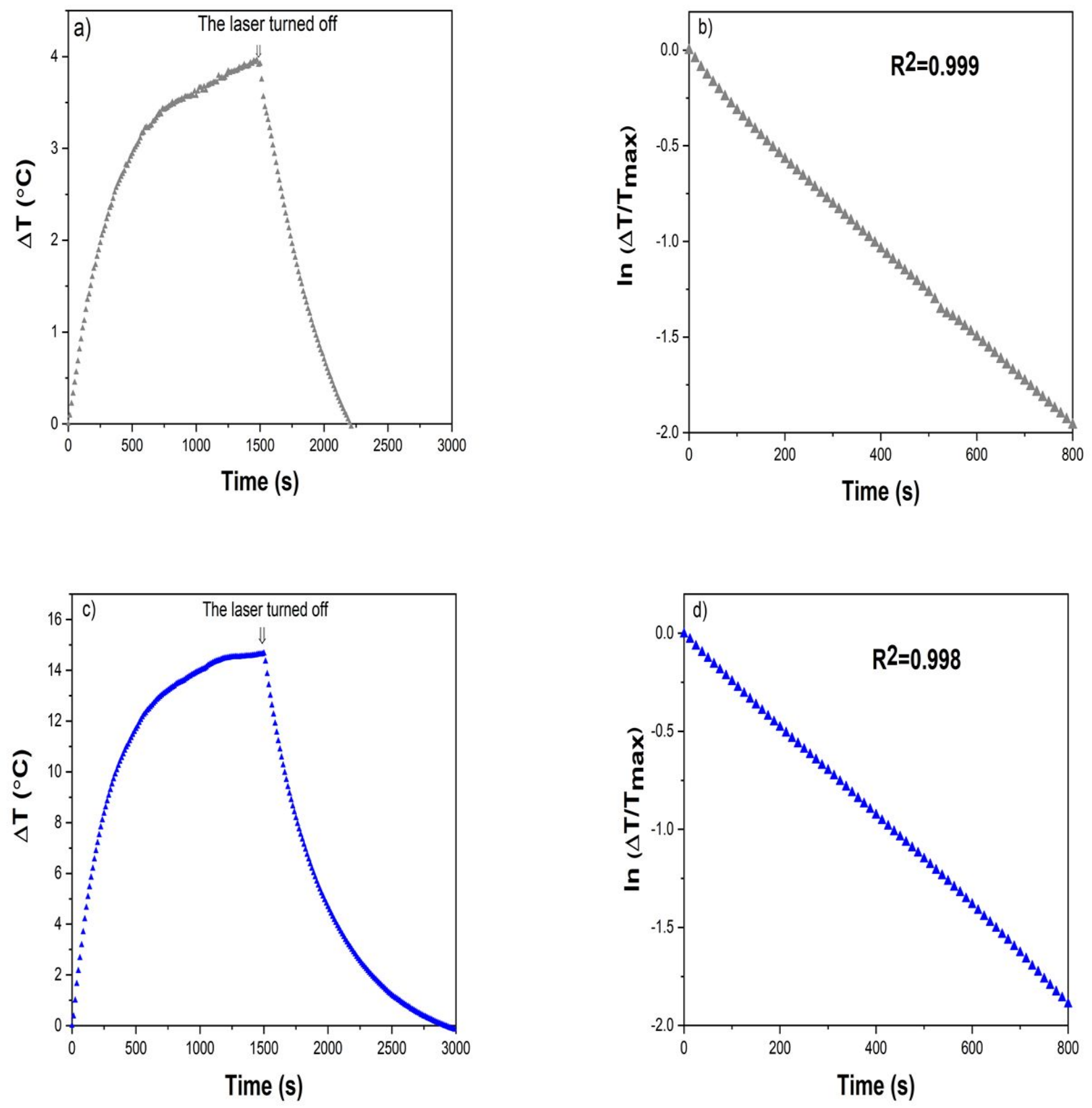

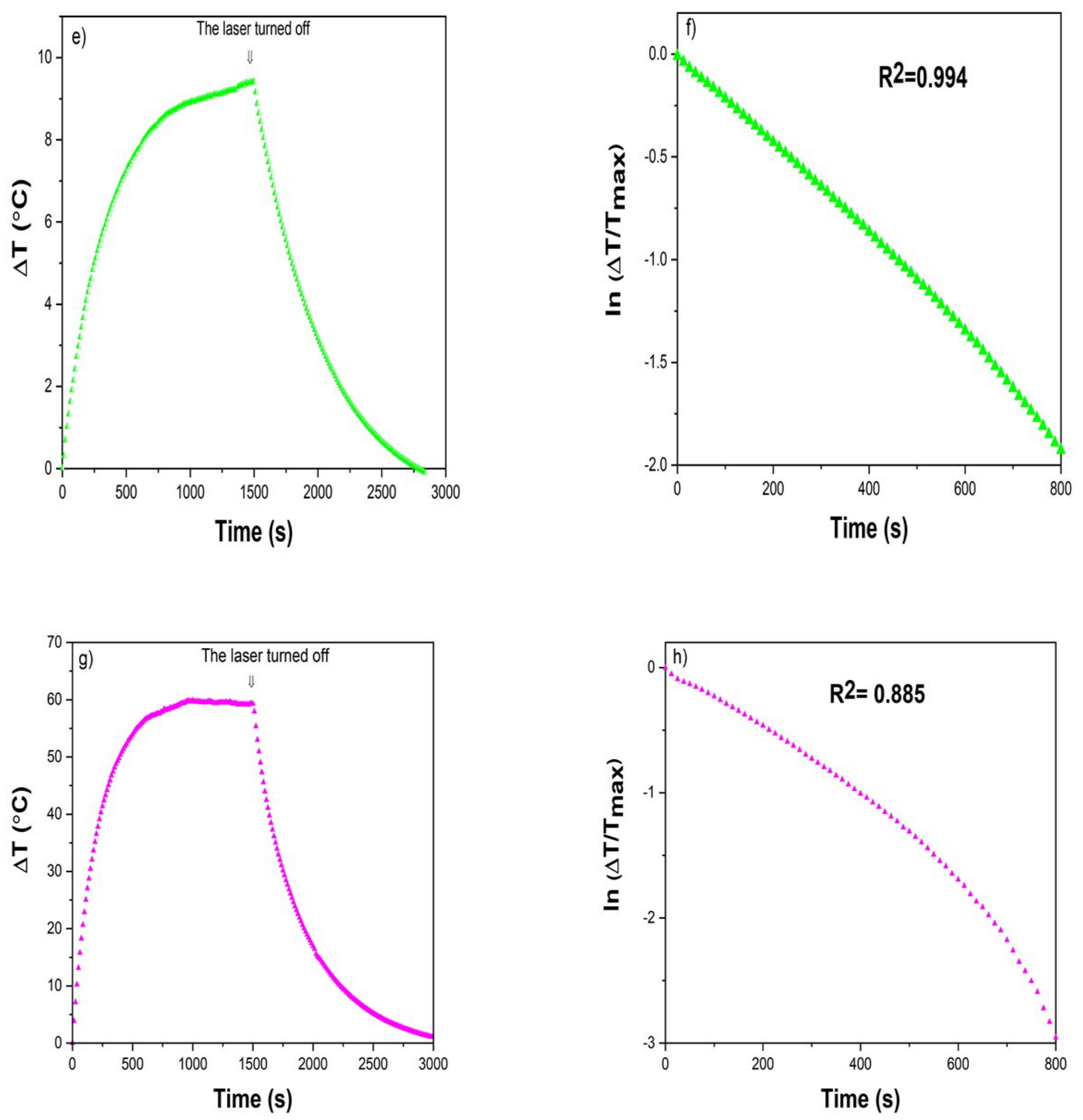

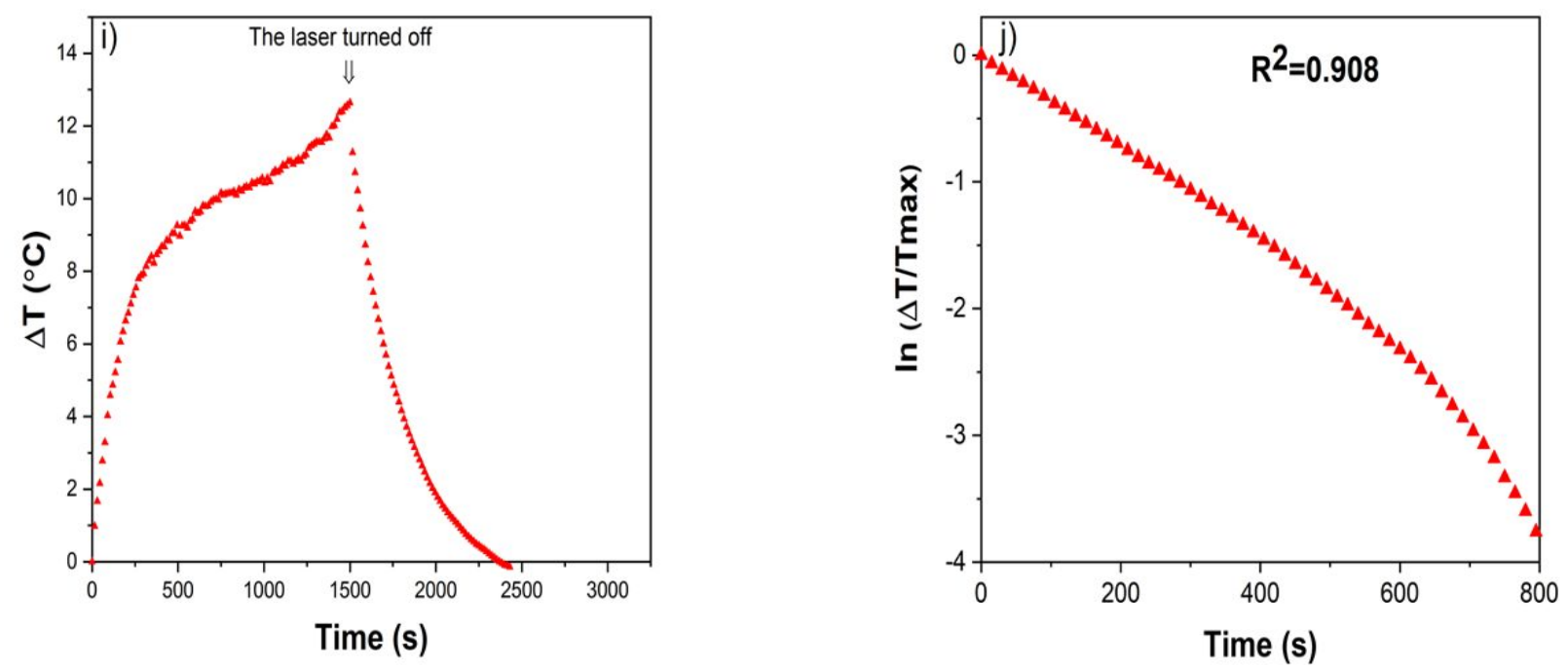

Figure S2. Heating and cooling temperature profiles of (a) $20 \mathrm{~nm} \mathrm{AuNP,} \mathrm{(c)} 80 \mathrm{~nm}$ GNU, (e) 650 $\mathrm{nm}$ absorbance GNRs, (g) $808 \mathrm{~nm}$ absorbance GNRs, and (i) AuNPC. The rate constant (B) associated with heat losses calculated by plotting the natural log of $\left(T(t)-T_{0} / T_{\max }\right)$ versus the time.On the right, The rate constant of heat losses of (b) $20 \mathrm{~nm}$ AuNPs, (d) $80 \mathrm{~nm}$ GNUs, (f) 650 $\mathrm{nm}$ abs. GNRs, (h) $808 \mathrm{~nm}$ GNRs, and (j) AuNPC. $\mathrm{R}^{2}$ indicates how the data are fitting to a linear model. 


\section{Transmitted Power Measured by a Power Meter}

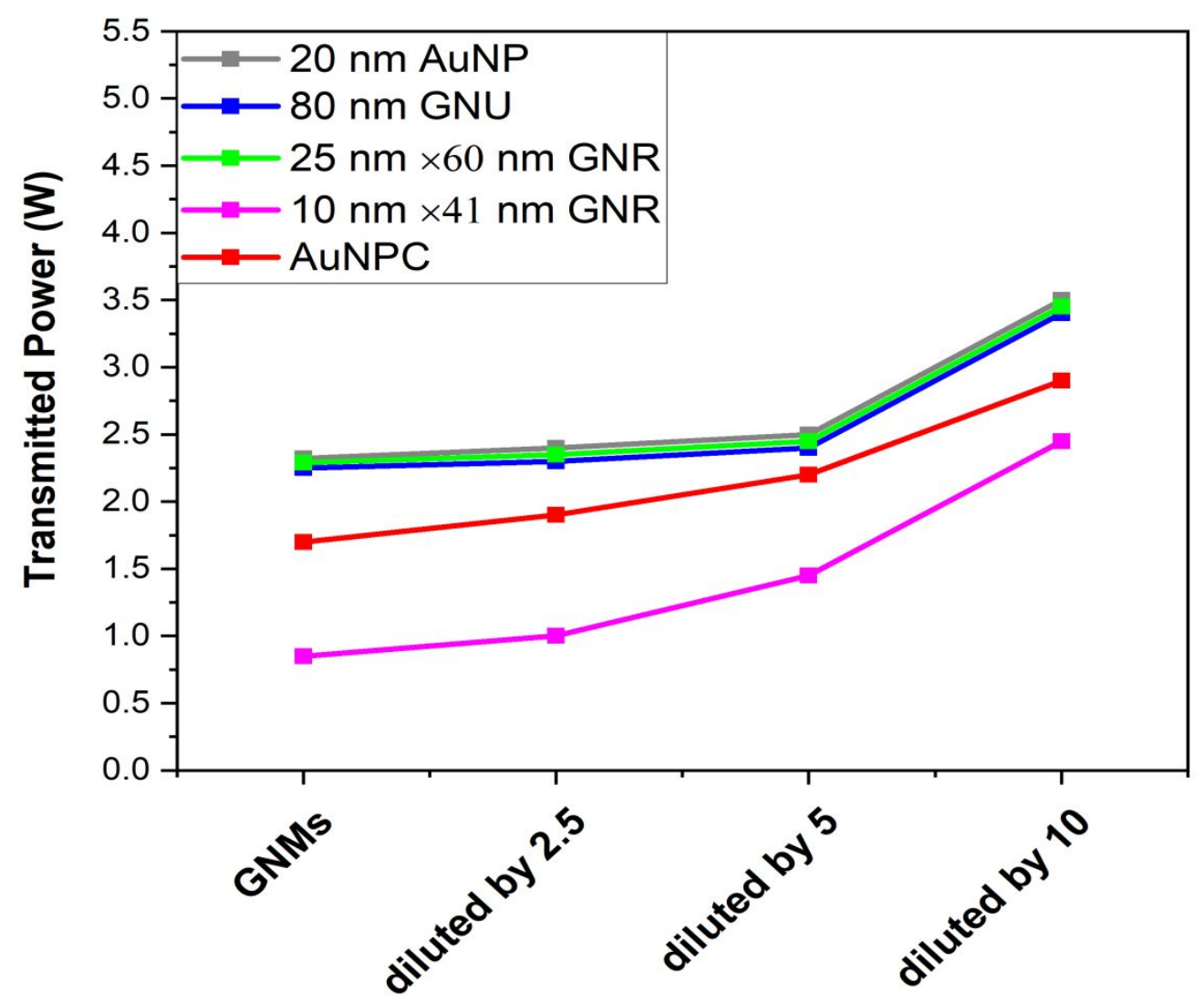

FigureS3. Transmitted power of $20 \mathrm{~nm}$ AuNPs, $80 \mathrm{~nm}$ GNUs, $650 \mathrm{~nm}$ and $808 \mathrm{~nm}$ abs. GNRs, and AuNPCs for different concentrations. GNMs means that the solution was not diluted (high concentration colloidal suspension). The transmitted power increases with decreasing concentration. The incident power was recorded at 3.78 Watts. 20, 25,80, and 10 indicate the diameters of GNMs. 


\section{Measured and Calculated Temperature Profiles}
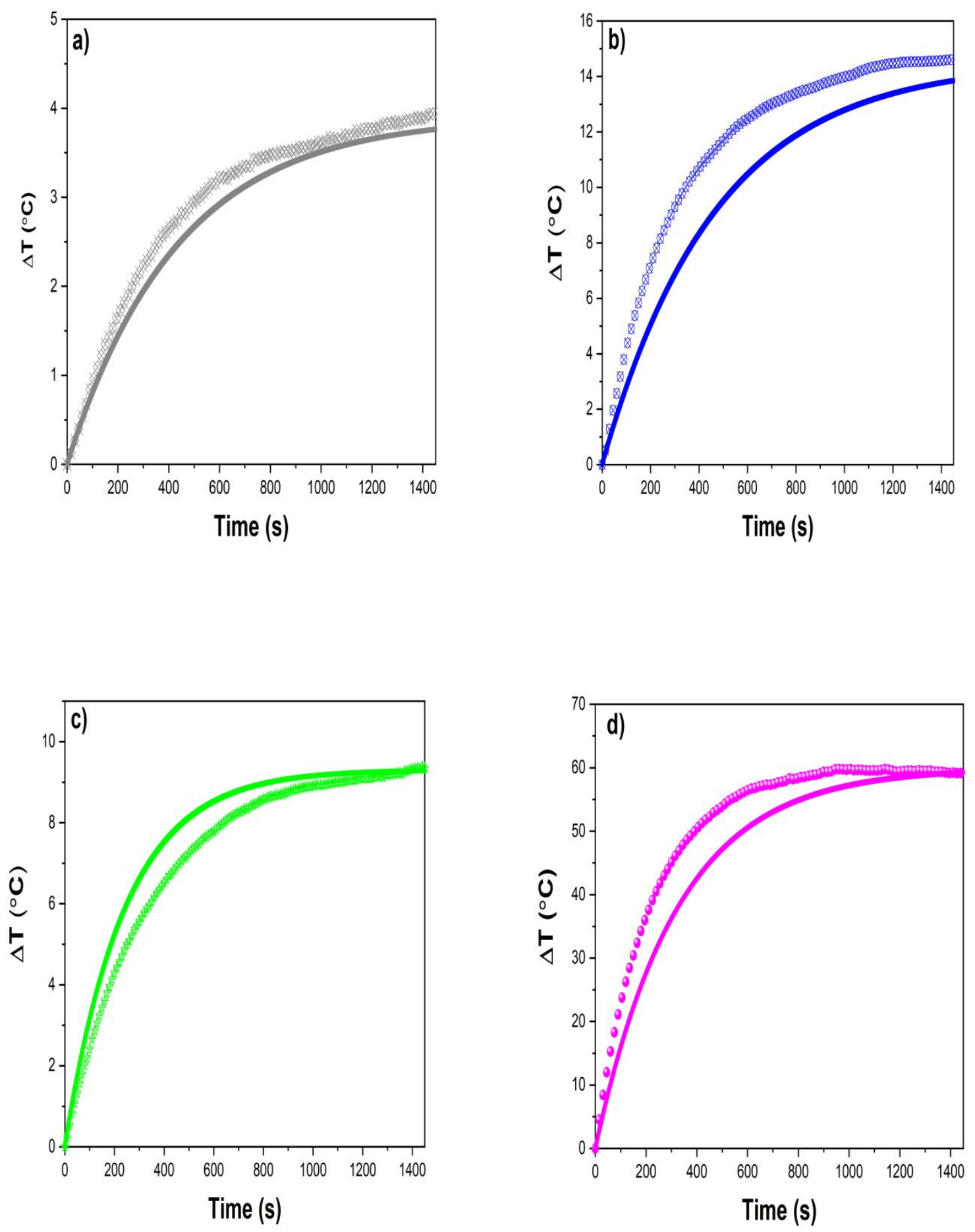


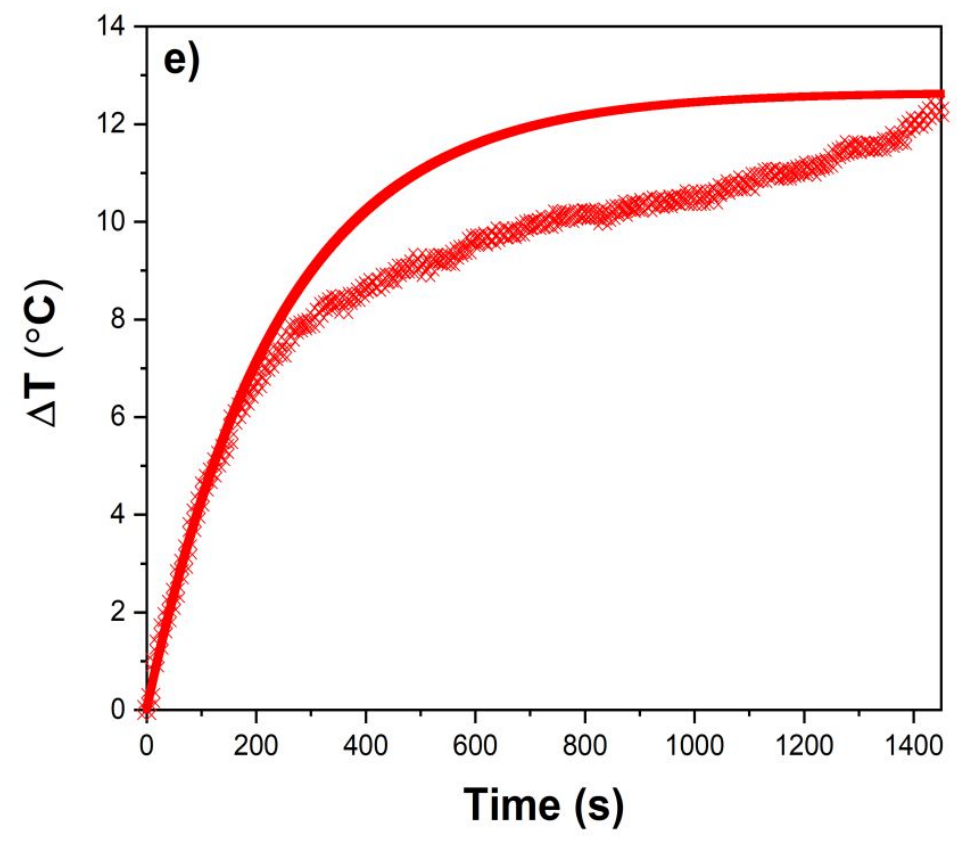

FigureS4. Experimental (symbols) and theoritical (solid line) temperature profiles of a) $20 \mathrm{~nm}$ AuNPs, b) $80 \mathrm{~nm}$ GNU, c) $25 \mathrm{~nm} \times 60 \mathrm{~nm}$ GNR, d) $10 \mathrm{~nm} \times 41 \mathrm{~nm}$ GNR, and e) AuNPC. 


\section{SEM images}

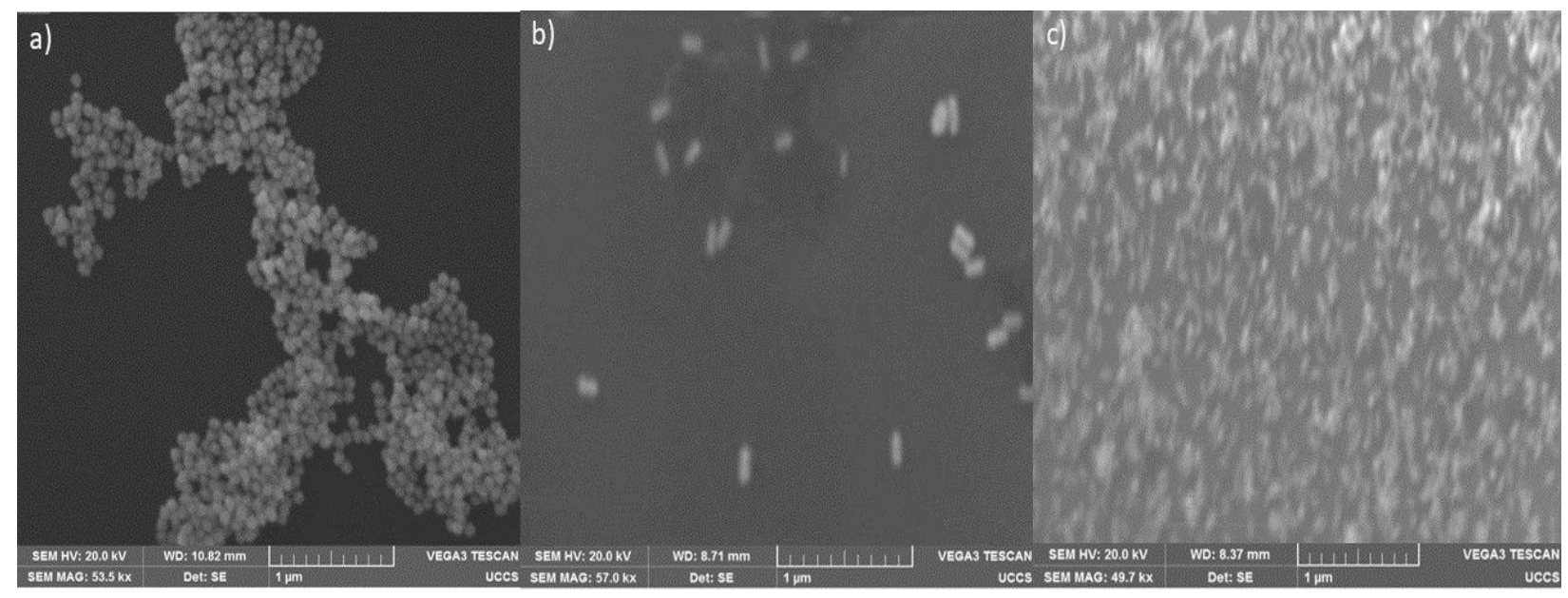

FigureS5. SEM images of a) $80 \mathrm{~nm}$ GNUs, b) $25 \mathrm{~nm} \times 60 \mathrm{~nm}$ GNRs, and c) $10 \mathrm{~nm} \times 41 \mathrm{~nm}$ GNRs. The SEM images of $20 \mathrm{~nm}$ AuNPs and AuNPs are not included. Further characterization of the $10 \times 41 \mathrm{~nm}$ GNRs is provided by Sigma-Aldirch (www.sigmaaldrich.com, product 716820).

TEM Images of AuNPC

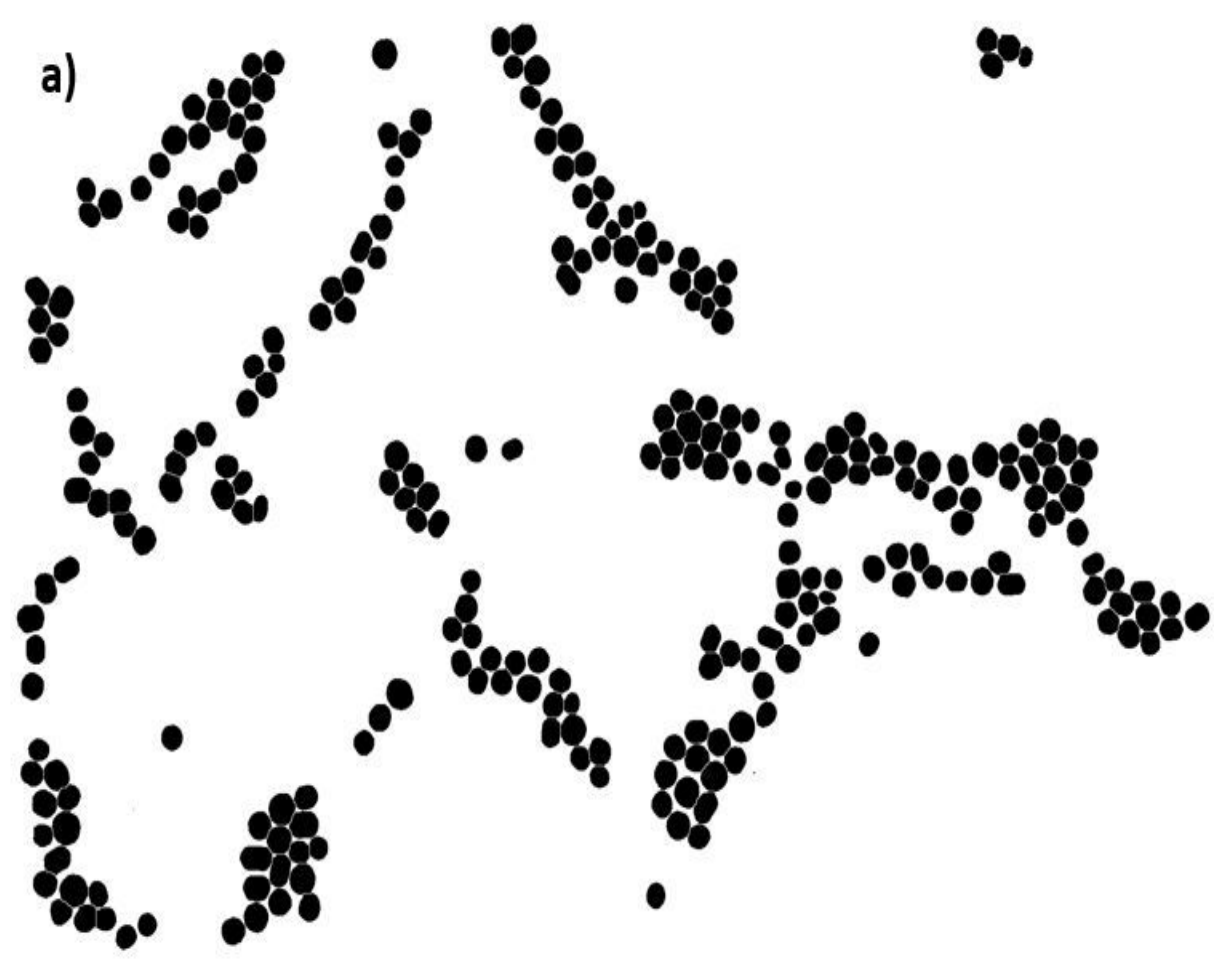




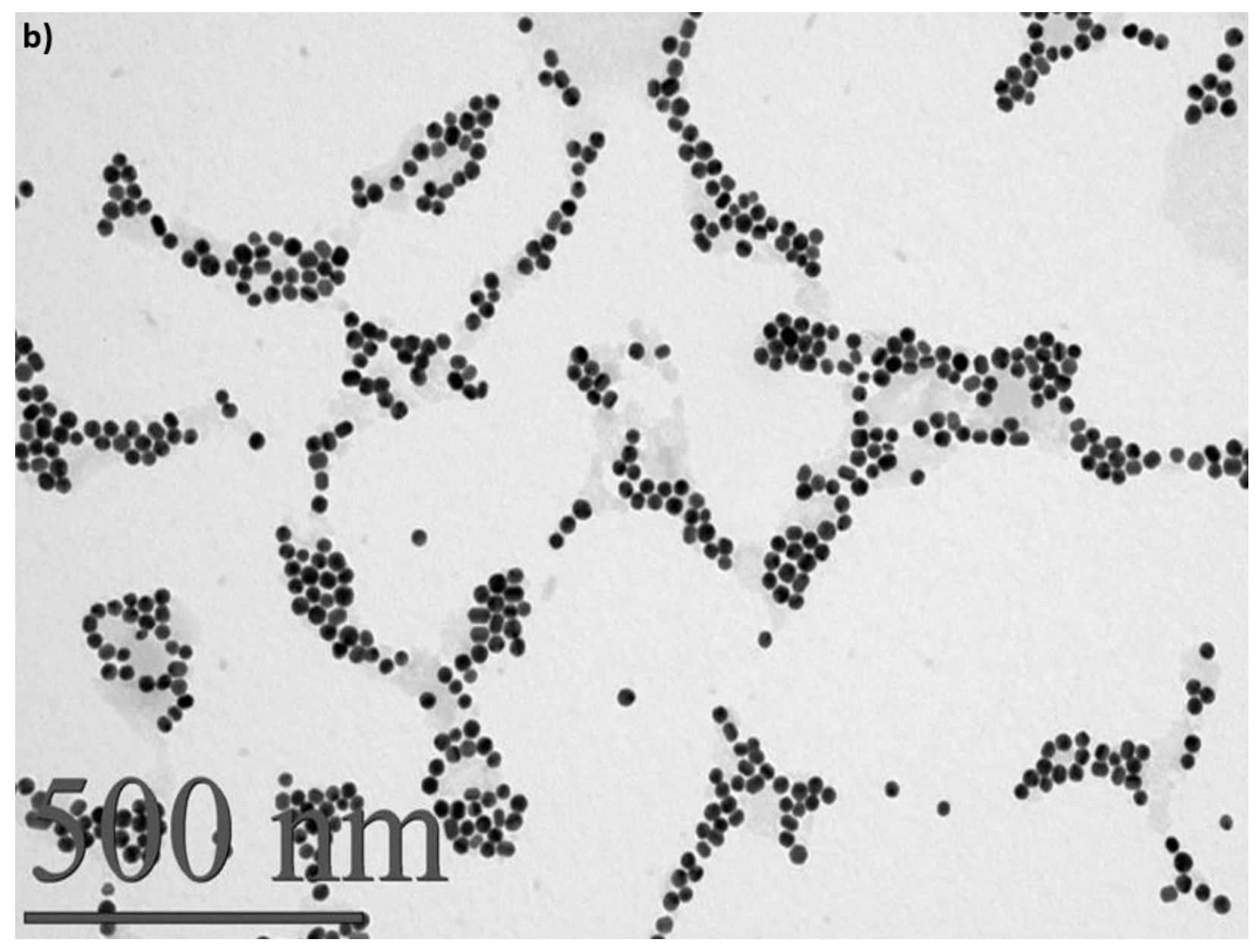

Figure S6. Transmission electron microscopy (TEM) images of AuNPC. A black and white contrast (a) and the original image (b)) are included to highlight the core diameter of the particles. 


\section{Schematic Showing where the Temperature Measured}

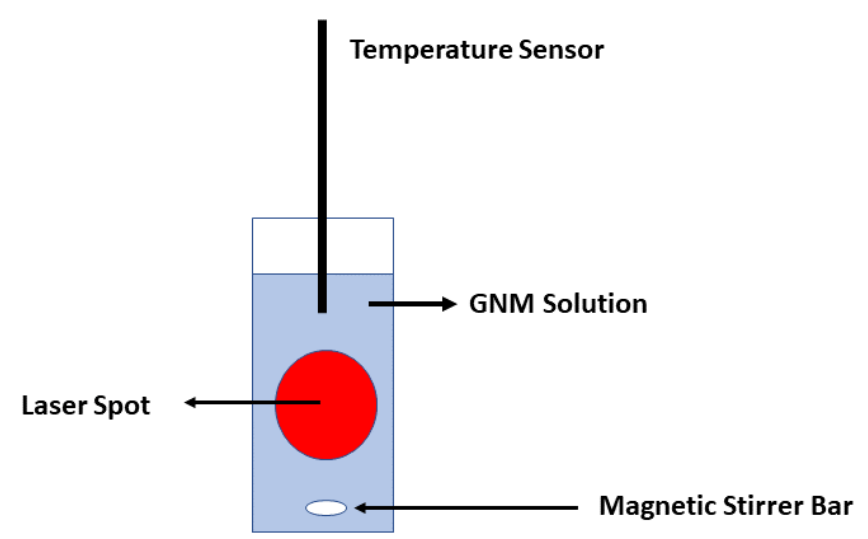

FigureS7. Schematic illustration showing the laser spot and the temperature sensor where the temperature measured. The volume of GNM solutions is $3 \mathrm{~mL}$ and it is the same volume for all GNMs.To provide the accuracy of the temperature measurements, the temperature sensor was carefully inserted into the solution and did not touch the laser spot during the laser activation. After the laser is inactivated, the temperature was measured at three different positions. It was found that the temperature is almost the same in different positions. For example, $80 \mathrm{~nm}$ GNU has temperature $14.6 \pm 0.8^{\circ} \mathrm{C}$. 


\section{Extinction Spectra of IR Dyes}

We experimentally obtained the photothermal conversion efficiency of the IR dye used to fuctionalize the spherical nanomaterial by following the method described in the theory. The photothermal conversion efficiency of the IR dye is 0.16 .

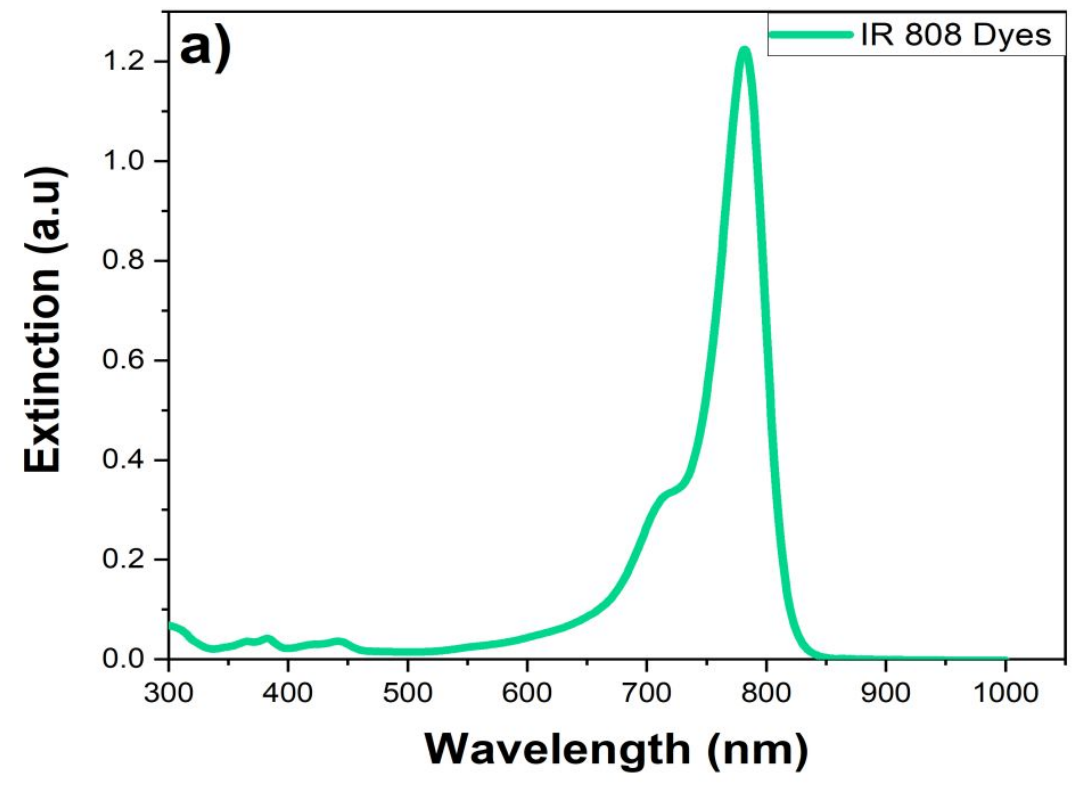

FigureS8.a) Uv-vis extinction spectra of IR 808 dye. 
Cooling GNM Solution and Determining the Temperature Rate

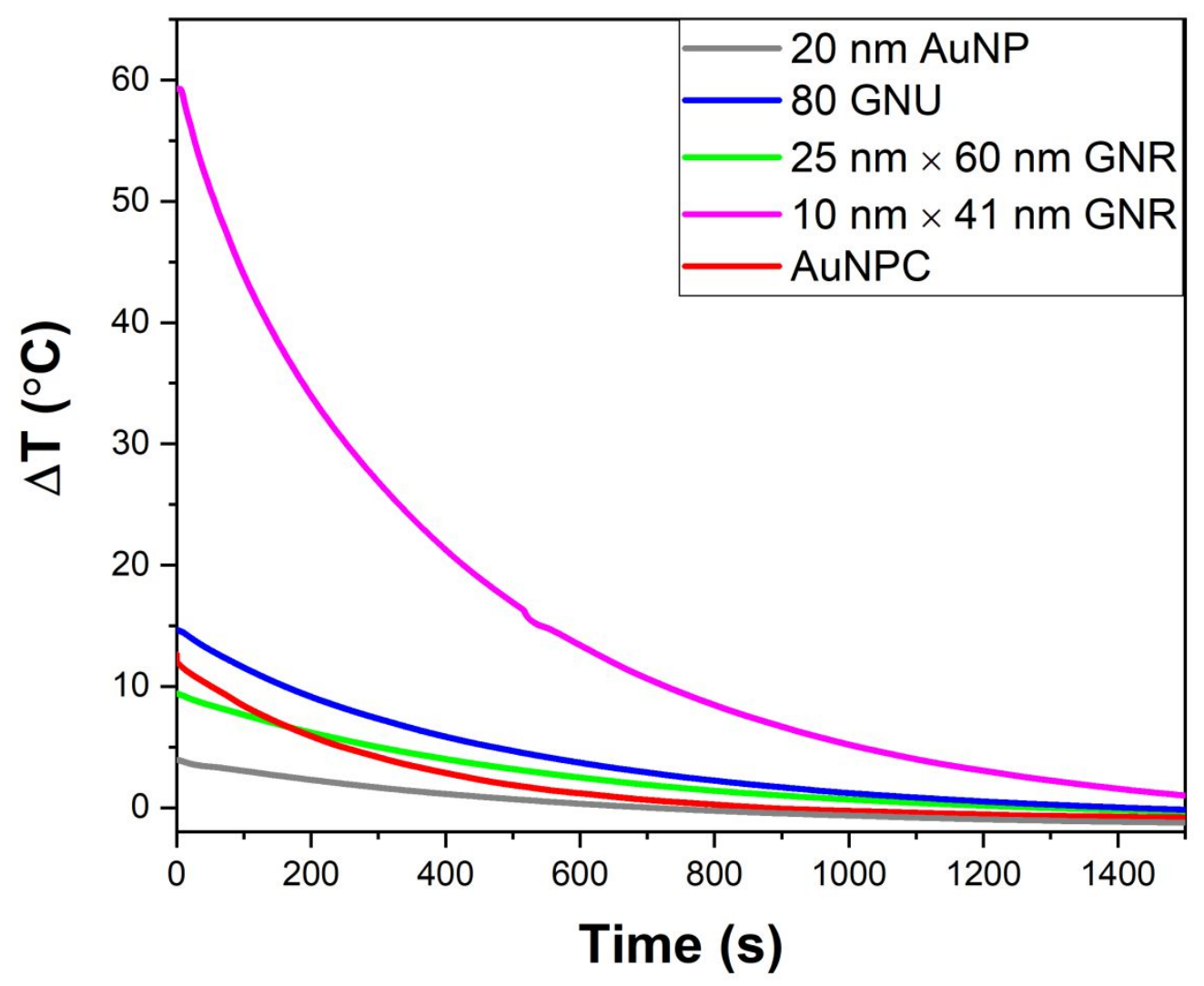

FigureS9. The cooling down data when the laser is off. 


\begin{tabular}{|l|l|l|l|l|l|}
\hline Morphology & $20 \mathrm{~nm}$ AuNP & $80 \mathrm{~nm} \mathrm{GNU}$ & $25 \mathrm{~nm} \times 60 \mathrm{~nm}$ GNR & $25 \mathrm{~nm} \times 60 \mathrm{~nm}$ GNR & AuNPC \\
\hline Heat Rate $\left({ }^{\circ} \mathrm{C} / \mathrm{s}\right)$ & $\begin{array}{c}0.00309 \pm 5.7 \times \\
10^{-5}\end{array}$ & $0.0084 \pm 1.9 \times 10^{-5}$ & $0.031 \pm 8 \times 10^{-5}$ & $\begin{array}{c}0.0058 \pm 1.15 \times \\
10^{-5}\end{array}$ & $0.0064 \pm 2.0 \times 10^{-5}$ \\
& & & & \\
\hline
\end{tabular}

TableS3. The cooling tempertaure rate associated with figureS8 and calculated by fitting data.

\section{Size Determination of GNMs Using Dynamic Light Scattering}

The effective (hydrodynamic) diameters of GNMs were measured using a BIC 90plus dynamic light scattering (DLS) (Brookhaven Instruments, ZetaPlus zeta potentials analyzer). The measurements were performed at the scattering (detecting) angle of 90 degrees and the measurement temperature was set to be at the room temperature $\left(23^{\circ} \mathrm{C}\right)$. The DLS instrument is supplied with a power $40 \mathrm{~mW}$ diode laser at $657 \mathrm{~nm}$ and supported by ZetaPALS Particle Sizing Software. It should be noted that determining the diameters based on the number distribution has less skewness compared to that based on the intensity distribution. the GNMs used in this study were obtained commercially. Thus, to give an accuracy of the nanoparticle size, the diameters based on the intensity, volume, and number distribution are provided. It should be noted that the particle size based on the volume distribution represents the radius not the diameter of nanoparticle sizes. Furthermore, GNRs exhibit two diameter peaks and these peaks do not correspond to the longitudinal and transverse dimensions, but rather the rotational diffusion coefficient. ${ }^{7}$ Additional DLS measurements taken by a different equipment were provided. 

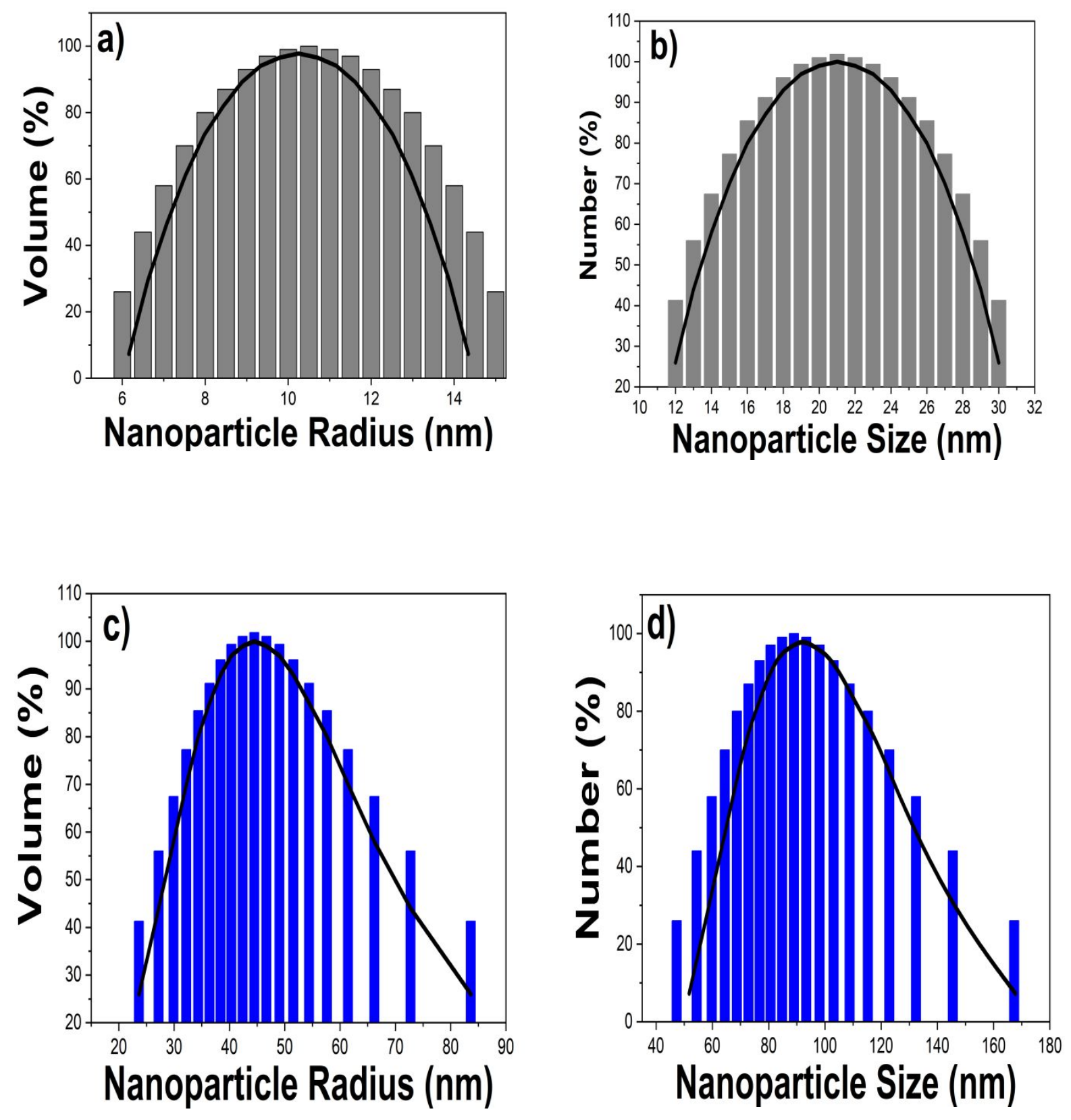

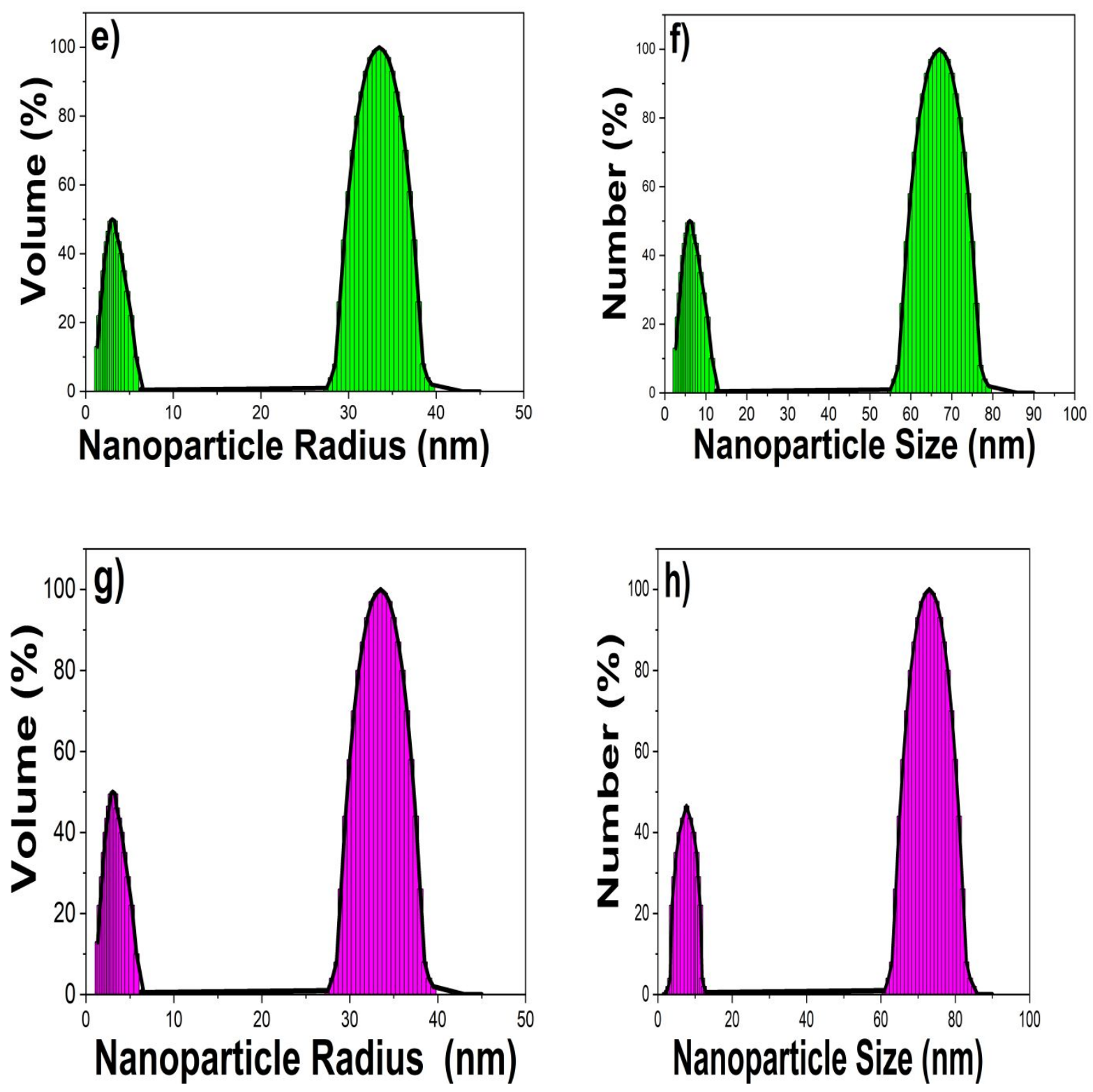

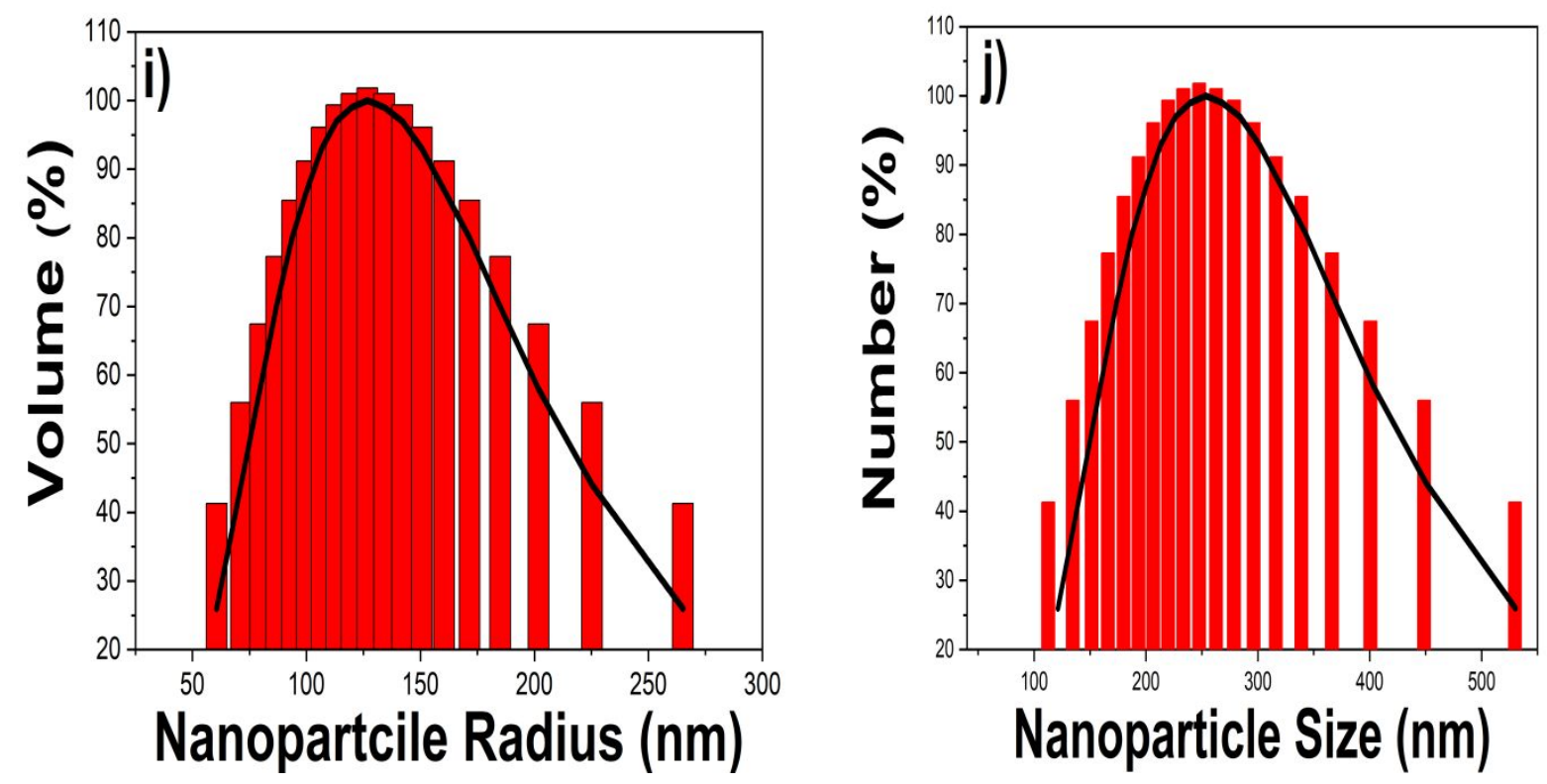

FigureS10. GNM volume and number distribuations. (a,c,e,g, and i) the nanoparticle radius based on the volume of $20 \mathrm{~nm}$ AuNP, $80 \mathrm{~nm}$ GNU, $25 \mathrm{~nm} \times 60 \mathrm{~nm}$ GNR, $10 \mathrm{~nm} \times 41 \mathrm{~nm}$ GNR, and AuNPC, respectively. (b,d,f,h and j) the nanoparticle size of based on the number distribution of $20 \mathrm{~nm}$ AuNP, $80 \mathrm{~nm}$ GNU, $25 \mathrm{~nm} \times 60 \mathrm{~nm}$ GNR, $10 \mathrm{~nm} \times$ 41nm GNR, and AuNPC, respectively. 


\section{DLS measurement in $0.025 \%$ Tween 20}

Results

\begin{tabular}{|c|c|c|c|c|c|}
\hline & & & Size (d.nm): & $\%$ Intensity: & St Dev (d.n... \\
\hline Z-Average (d.nm): & 180.0 & Peak 1: & 247.0 & 100.0 & 129.5 \\
\hline Pdl: & 0.266 & Peak 2: & 0.000 & 0.0 & 0.000 \\
\hline Intercept: & 0.922 & Peak 3: & 0.000 & 0.0 & 0.000 \\
\hline
\end{tabular}

Result quality : Good

Size Distribution by Intensity

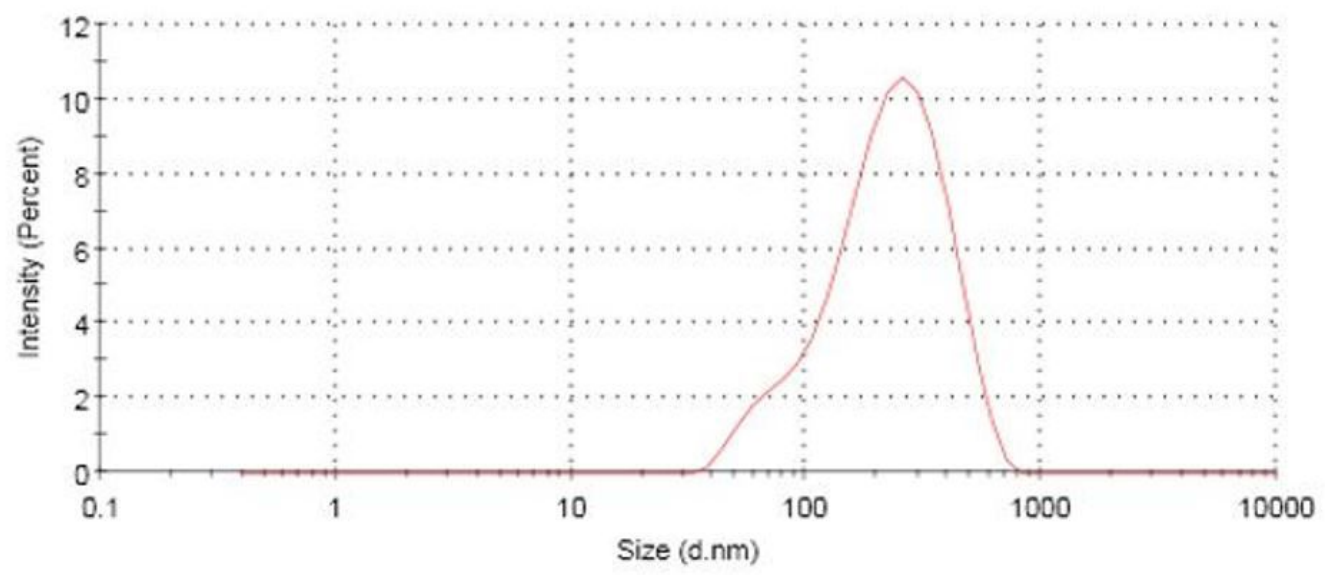

Record 16: 2019-07-18_CTI Samples (20nm AUNP with Dye in 0.025\% Tween 20 and PBS) 1 ]

DLS measurement in $\mathrm{pH} 4$ acetic acid 


\section{Results}

\begin{tabular}{|c|c|c|c|c|c|}
\hline & & & Size (d.nm): & $\%$ Intensity: & St Dev (d.n... \\
\hline Z-Average (d.nm): & 392.8 & Peak 1: & 364.7 & 100.0 & 122.4 \\
\hline Pdl: & 0.303 & Peak 2: & 0.000 & 0.0 & 0.000 \\
\hline Intercept: & 0.944 & Peak 3: & 0.000 & 0.0 & 0.000 \\
\hline
\end{tabular}

Result quality : Good

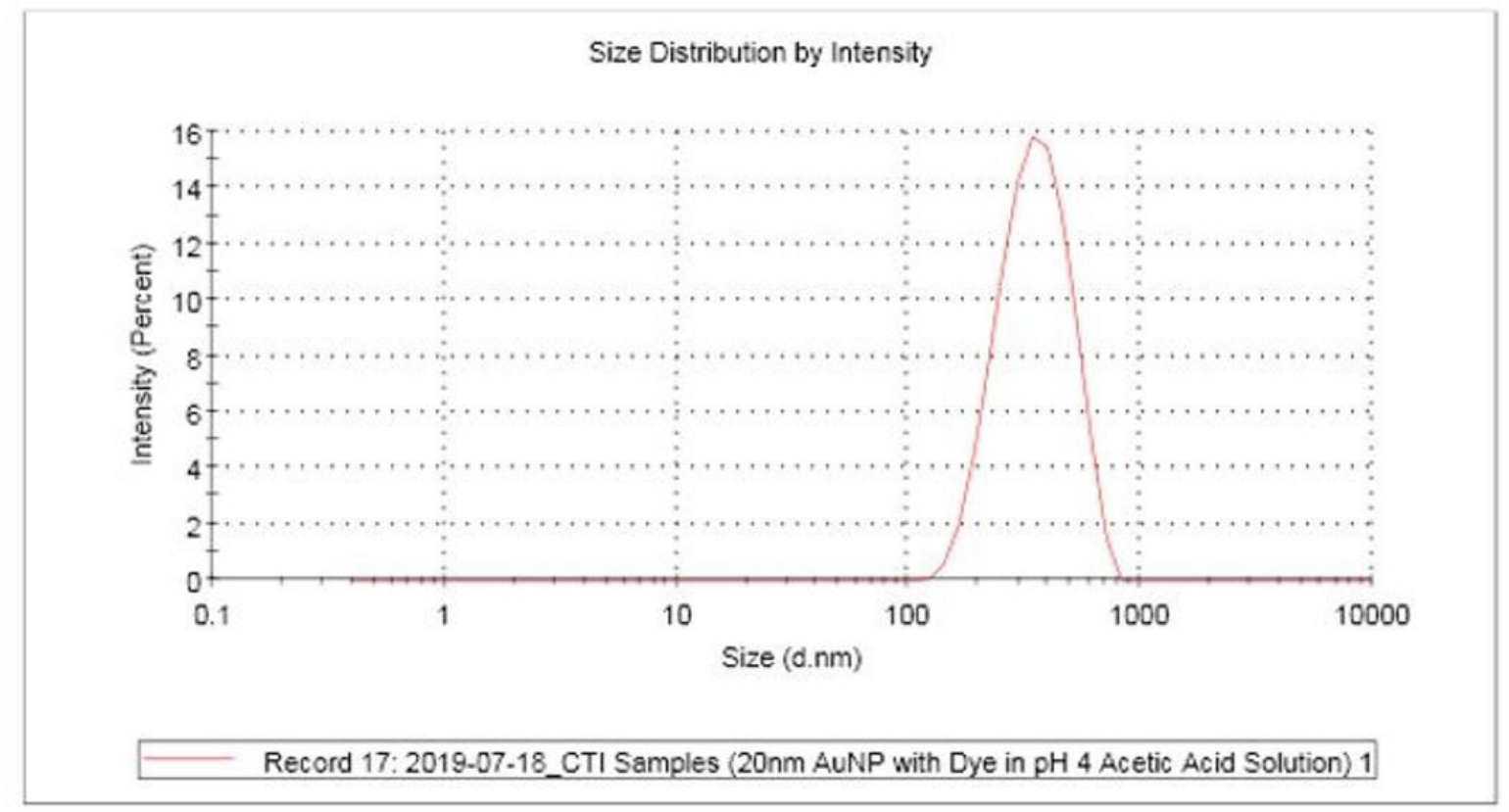

FigureS11. Additional DLS measurements for AuNPC acquired on a Malvern Pananalytical Zetasizer in $0.25 \%$ Tween 20 (top) and pH 4 acetic acid (bottom). 


\section{REFERENCES}

1- Richardson, H. H.; Carlson, M. T.; Tandler, P. J.; Hernandez, P.; Govorov, A. O. Experimental and Theoretical Studies of Light-to-Heat Conversion and Collective Heating Effects in Metal Nanoparticle Solutions. Nano Lett. 2009, 9, 11391146.

2- Jiang, K.; Smith, D. A.; Pinchuk, A. Size-Dependent Photothermal Conversion Efficiencies of Plasmonically Heated Gold Nanoparticles. J. Phys. Chem. C 2013, 117, 27073-27080.

3- Chen, H.; Shao, L.; Ming, T.; Sun, Z.; Zhao, C.; Yang, B.; Wang, J. Understanding the Photothermal Conversion Efficiency of Gold Nanocrystals. Small 2010, 6, 2272-2800.

4- Cole, J. R.; Mirin, N. A.; Knight, M. W.; Goodrich, G. P.; Halas, N. J. Photothermal Efficiencies of Nanoshells and Nanorods for Clinical Therapeutic Applications. J. Phys. Chem. C 2009, 113, 12090-12094.

5- Pattani, V. P.; Tunnell, J. W. Nanoparticle-Mediated Photothermal Therapy: A Comparative Study of Heating for Different Particle Types. Lasers Surg. Med. 2012, 8, 675-684.

6- Zeng, J.; Goldfeld, D.; and Xia, Y. A Plasmon-Assisted Optofluidic (PAOF) System for Measuring the Photothermal Conversion Efficiencies of Gold Nanostructures and Controlling an Electrical Switch. Angew. Chem 2013, 52, 41694173.

7- Liu, H.; Pierre-Pierre, N.; Huo, Q. Dynamic Light Scattering for Gold Nanorod Size Characterization and Study of Nanorod-Protein Interactions. Gold Bull. 2012, 45, 187-195. 